\title{
Study the Effect of Multilayer Single Point Incremental Forming on Residual Stresses for Bottom Plates
}

\author{
Aseel Hamad Abed* \\ Aqeel Sabree Bedan** \\ Mohanad Faeq Noori**** \\ ***,***Department of Production Engineering and Metallurgy / University of Technology \\ ***Email: Mohuned_2007@yahoo.com
}

(Received 24 October 2016; accepted 22 February 2017)

https://doi.org/10.22153/kej.2017.02.004

\begin{abstract}
Knowing the amount of residual stresses and find technological solutions to minimize and control them during the production operation are an important task because great levels of deformation which occurs in single point incremental forming (SPIF), this induce highly non-uniform residual stresses. In this papera propose of a method for multilayer single point incremental forming with change in thickness of the top plate $(0.5,0.7,0.9) \mathrm{mm}$ and lubrication or material between two plates(polymer, grease, grease with graphite, $\operatorname{mos}_{2}$ ) to knowing an effect of this method and parameters on residual stresses for the bottom plates. Also compare these results for the bottom plates with the single plate at same thickness $0.9 \mathrm{~mm}$. The results showed that when increase thickness of the top plate the value of residual stresses will decrease for bottom plates and when used graphite with grease between two plates gives less residual stresses (R.S = 60.173 MPa.) reverse when used Mos2 which will gives a larger residual stresses (R.S = 146.617 MPa.) in the bottom plate.
\end{abstract}

Keywords: Multilayer Single Point Incremental Forming (SPIF), Residual Stresses, Lubrication.

\section{Introduction}

Incremental forming is a flexible sheet metal forming operation that uses simple generic and in inexpensive made tools to locally deform a sheet of metal along a predefined tool path without counting on dies. The operation is conducted at room temperature and requires a CNC machining center, a round tip tool and a simple support to fix the sheet being formed [1]. In SPIF there is only support for work-piece between the two ends but no support for the tool. The blank sheet is clamped in a universal stationary blank holder and the forming tool describes the contour of the desired geometry controlled by a regular CNC machine Figure (1) [2]. By depending on how to interact external loads with residual stresses, they can influence the mechanical behavior and the lifetime of components in a negative or positive way. For example, surface tensile residual stresses are harmful to fatigue resistance and even in the not found of an applied stress the existence of a corrosive environment may reason stress corrosion cracking but compressive residual stresses will advance the fatigue resistance level since the residual stresses and applied stresses are additive [2].

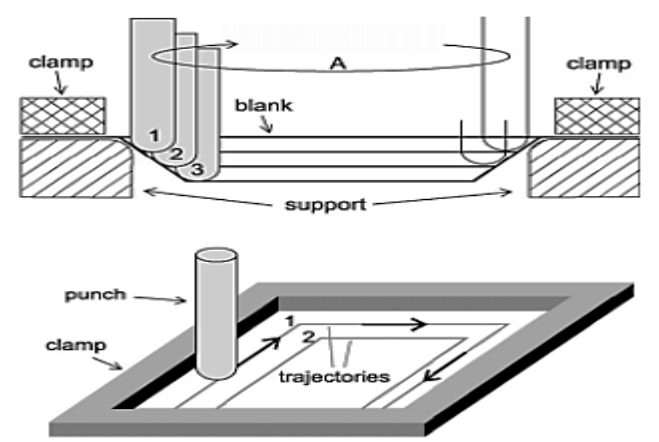

Fig. 1. Schematic of single point incremental forming process [2]. 


\section{Setup of Multilayer SPIF}

Multilayer single point incremental forming is the idea of using two plates at the same time, as shown in Figure (2), in traditional SPIF the surface will be affected by the high degree of relative movement between plate and forming tool. Using a multi-plate, all this sliding is only affecting on the top plate. The relative movement between the top and bottom plate is very small. The forming process in two plates at the same time will increase process forces. In most cases it will be desirable to keep the thickness of the upper sheet at a minimum. Friction between the sheets will among other factors determine how much the plates act like one plate or like two separate plates on top on each other.

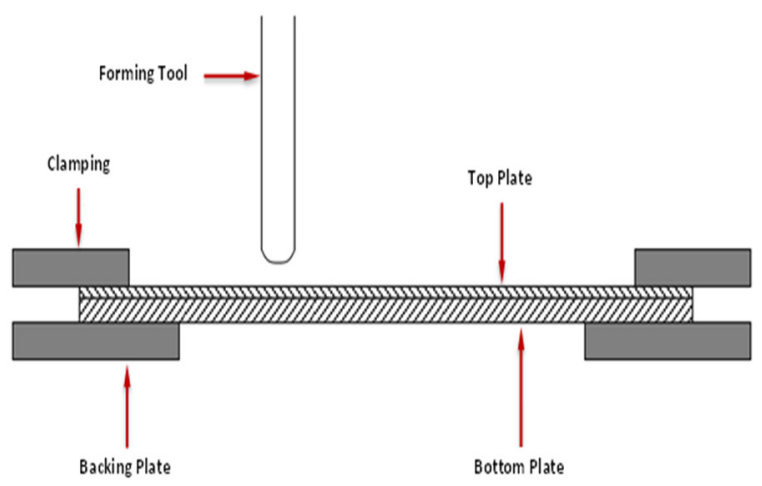

Fig. 2. SPIF using two plates [3].

\section{Experimental Work}

In this paper, the SPIF was carried out without die and by using 3-axis perpendicular CNC machine. and by using Matlab software the CAD model of the final shape is created (illustrated in Figure (3)).

The following steps present the experimental work in this paper which includes:-

- By using Matlab software Generating the CAD model.

- Generating toolpath using Matlab software.

- Forming using vertical CNC milling machine.

- Residual Stress test.

- We proposed and used aisoplaner tool path for axisymetrical parts. Figure (4) illustrated the final part that product in this paper.

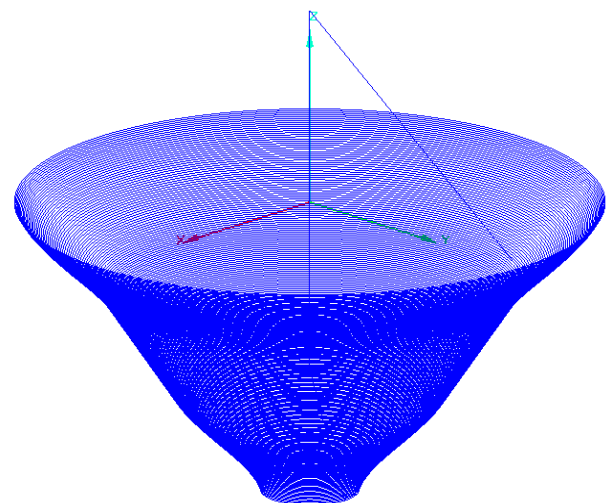

Fig. 3. By using Matlab software created the CAD model of the final product.

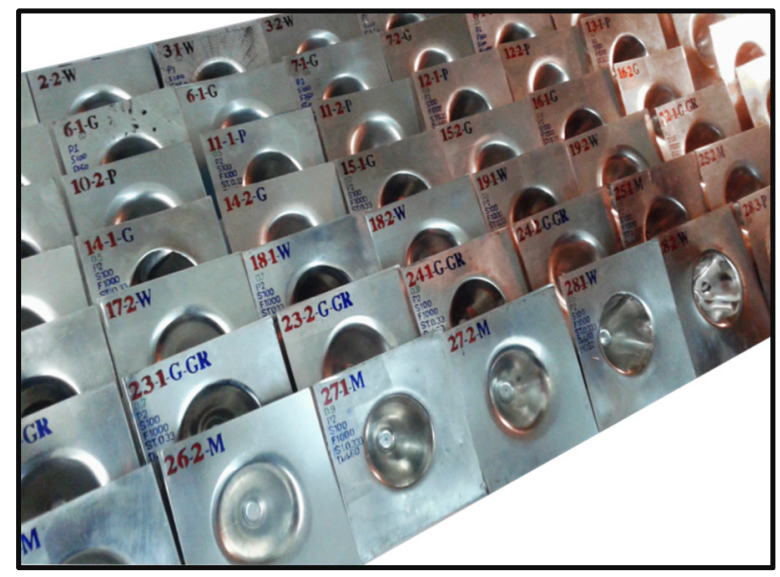

Fig. 4. The final product is created using Single point incremental forming.

\section{Sheet Material}

In all experiments carried out, sheet metals of an Aluminum AA1050 alloy are used. The initial dimension of the sheet is $225 \times 225 \mathrm{~mm}$, while the working area with diameter $120 \mathrm{~mm}$ according to the blank holder size as shown in Figure (5).

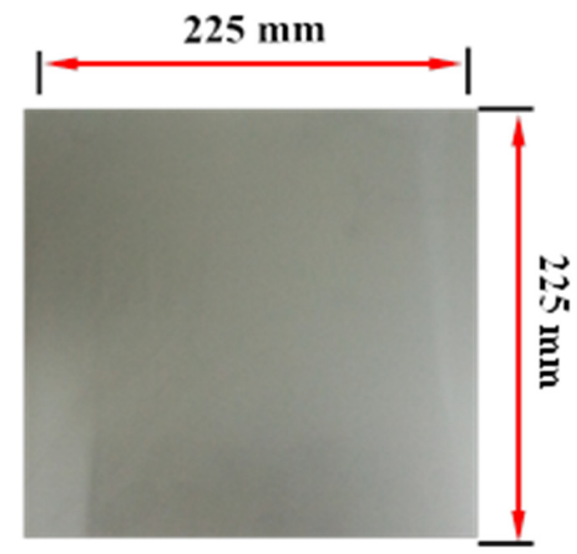

Fig. 5. Size of Aluminum blank used in this work. 
The first step must be defined the mechanical properties and chemical for each one and after that select the geometric condition many kinds of test is as follow:

\section{A. Chemical composition}

The chemical composition of the sheet material is listed in Table (1).

Table 1,

Chemical composition of the Aluminum AA 1050

sheet.

\begin{tabular}{lll}
\hline Element & Measured & ISO. \\
\hline $\mathrm{Al}$ & 99.4 & $0-99.5$ \\
$\mathrm{Mg}$ & 0.026 & $0-0.05$ \\
$\mathrm{Ti}$ & 0.003 & $0-0.05$ \\
$\mathrm{Zn}$ & 0.0406 & $0-0.07$ \\
$\mathrm{Mn}$ & 0.038 & $0-0.05$ \\
$\mathrm{Fe}$ & 0.31 & $0-0.4$ \\
$\mathrm{Cu}$ & 0.041 & $0-0.05$ \\
$\mathrm{Si}$ & 0.142 & $0-0.25$ \\
\hline
\end{tabular}

\section{B. Tensile test}

Figure (6) present tensile test. Because the strength in this way is minimum according to literature, therefore these tests result in $\left(90^{\circ}\right.$ to rolling direction). But due to an axisymmetric product the most of the experimental work down in isotropic condition. These results are as shown in Tables (2).
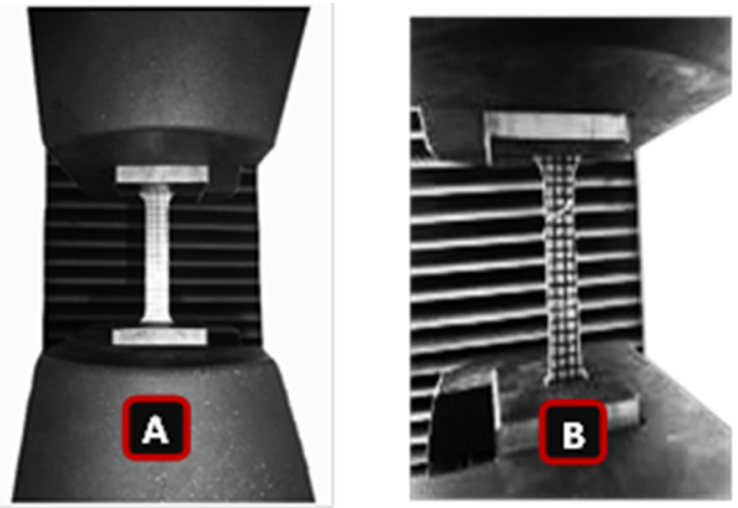

Fig. 6. Tensile test device with a specimen (A) Before test (B) After test.

Table 2,

Mechanical properties of Aluminum 1050

\begin{tabular}{lll}
\hline Element & Measured & ISO. \\
\hline Tensile & 109 & $105-145$ \\
Strength MPa. & & $70-75$ \\
Modulus Elasticity Gpa. & 70 & $\geq 85$ \\
Yield strength & 95 & $20-30$ \\
(Min)MPa. & 28 & $2-6$ \\
Vickers Hardness VPN & 4 & 0.33 \\
Elongation & 0.33 & \\
Poisson Ratio & & \\
\hline
\end{tabular}

\section{Preparation of the specimens for residual stresses testing}

In order to conduct residual stresses testing the dimensional of specimens must be specific because the dimensions of specimens which the device of residual stresses can test it has a limited dimension, Figure (7) explanation how works the specimens for residual stresses testing.
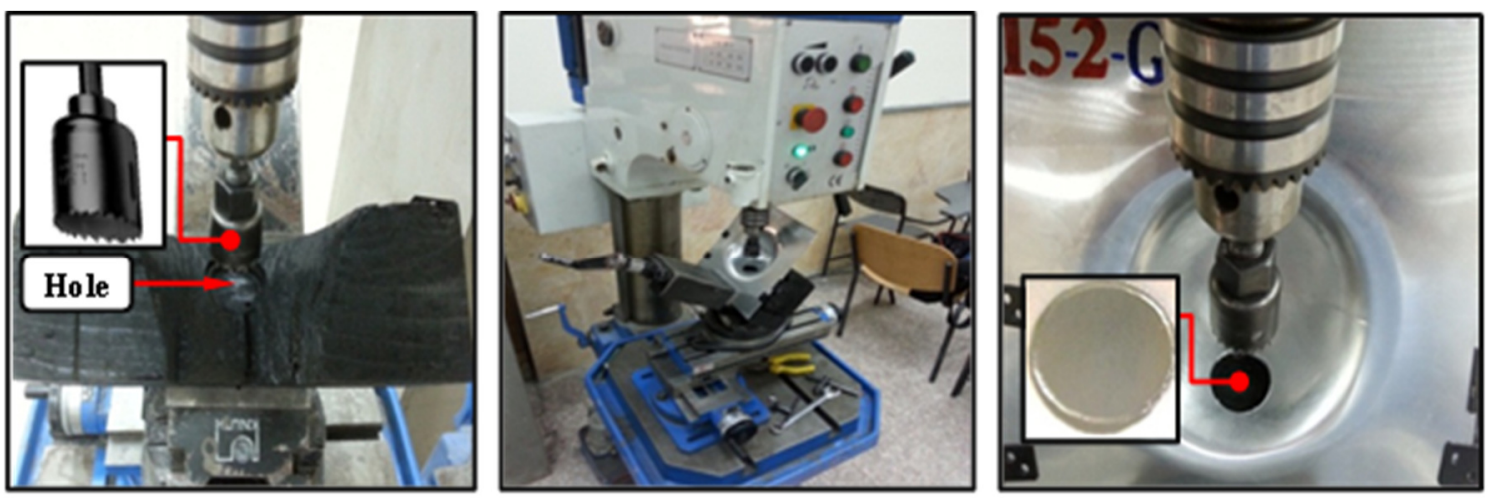

Fig. 7. Preparation of the specimens for residual stresses test. 


\section{Change Parameters Used in This Work 5.1 Thickness of Top Plate}

Change in thickness of top plate at $(0.5,0.7$, and 0.9) In order to know effect of change it on residual stresses of bottom plate. The Figure (8) shown two plates after incremental forming.

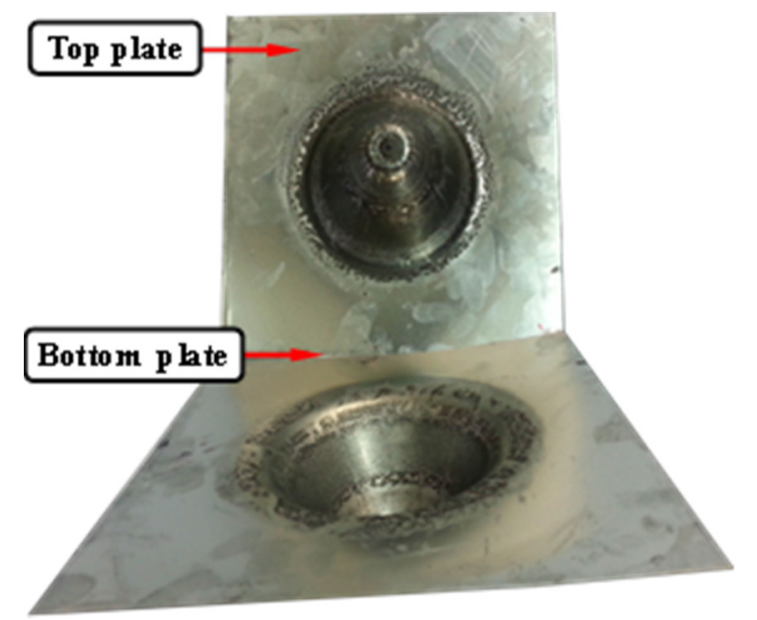

Fig. 8.Two plates after incremental forming.

\section{2 lubrication or Material Between Two Plates}

Polymer, $\operatorname{mos}_{2}$, grease and graphite with grease are successful lubrication or material which used between two plates in order to know effect these lubrication or material on residual stresses for bottom plates, Figure (9) shown successful lubrication or material that used in this work.

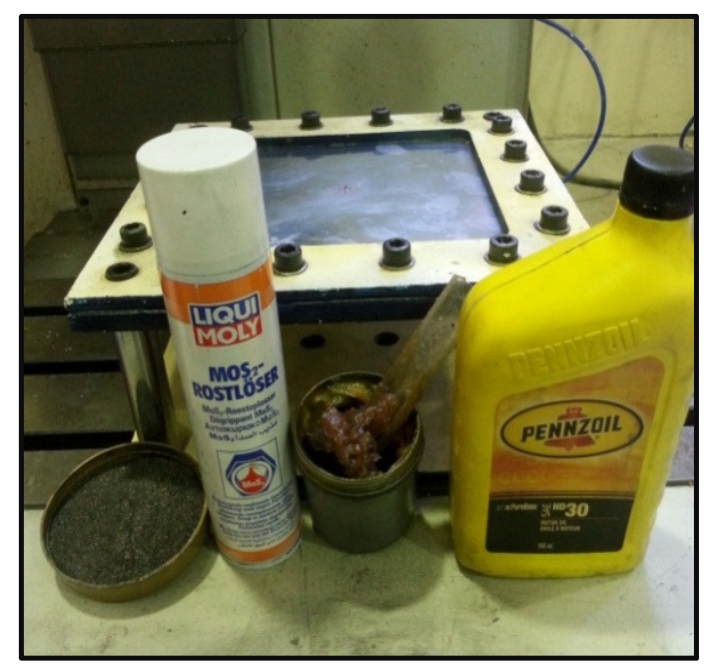

Fig. 9. Some successful lubrication or material that used in this work.

\section{Lubrication used on Top Plates}

During SPIF process, the tool was rotated at spindle speed and the tool head pressed on sheet metal that cause local plastic deformation. The head of tool was subjected to friction and wear of tool also heat is generated when the tool rotate and move along the tool path. This has an effect on the surface quality. In order to decrease these effects between the forming tool and the sheet, many studies have been made to select a suitable lubricant, better type of lubrication that used for SPIF is an oil SAE 30. In this work used Pennzoil SAE 30 used manually as lubricant throughout the experiments as shown in Figure (10). This oil has density of $\left(0.88 \mathrm{~g} / \mathrm{mm}^{3}\right)$ at $15.6^{\circ} \mathrm{C}$ and viscosity index of 105 [4]. The lubrication is utilized so that the cavity of the forming part is filled with oil at all the time during forming. Consequently, beside lubrication, the oil provides the forming process as cooling fluid.

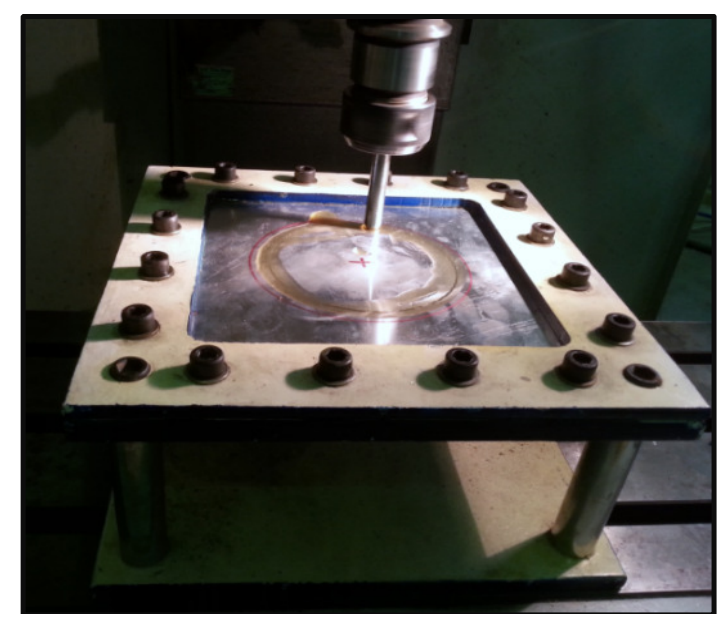

Fig. 10. Lubrication on top plates during SPIF.

\section{Residual Stresses Test}

The forming surface was measured at four different angles using a ORIONRKS 6000 test (the X-ray diffraction technology was used to detect the residual stress) measuring instrument with the angles $\left(0^{\circ}, 15^{\circ}, 30^{\circ}\right.$ and $\left.45^{\circ}\right)$ and the average residual stress value is recorded in (MPa.) that illustrated in figure (5), the residual stress in original blanks is (-6.29MPa.). This specialized type of stress analysis system using the sideinclination method include stress analysis software, the stress analysis sample stand and Xray tube. X-ray stress analysis is very used to 
measurement the level of stress in the material. In the X-ray diffractometry of stress so few changes in the lattice space are measured from the X-ray diffraction pattern profile. The accuracy measurement of the residual stress let the use of the special stress analysis stands connected with the side inclination method. Free of absorption error is use in this technique. The software includes following functions, as measurement, peak position calculation, width at half height and stress calculation depending on the type of reflective plane and sample, either the Co tube or $\mathrm{Cr} \mathrm{X}$-ray tube is necessary. The acting single stress measure in four ways in the surface $\sigma_{\phi}$. Shows an isotropic solid that the strain along an inclined line according to elasticity theory ( $\mathrm{m} 3$ in Figure 5) is: [6]

$$
\begin{gathered}
\varepsilon_{\emptyset \psi}=\frac{1+v}{E}\left(\sigma_{1} \cos ^{2} \phi+\sigma_{2} \sin ^{2} \phi\right) \sin ^{2} \psi \\
-\frac{v}{E}\left(\sigma_{1}+\sigma_{2}\right)
\end{gathered}
$$

Use the strains to evaluate the stresses when take the strains in terms of inter-planar spacing and then it can be shown that

$\sigma_{\varnothing}=\frac{E}{(1+v) \sin ^{2} \psi}\left[\frac{d_{\psi}-d_{n}}{d_{n}}\right]$

$\varepsilon_{\emptyset \psi} \quad$ Strain measured in the $\phi \psi$ direction -

v Poisson's ratio

E Elastic modulus

$\mathrm{GPa}$

$\sigma_{1}, \sigma_{2}$ Principal stresses

MPa

Angle between the direction the

$\phi \quad$ sample and the projection in normal of the diffracting plane

deg.

Angle between the normal of the

$\psi \quad$ diffracting plane and the normal of deg. the sample.

$d_{\psi} \quad$ Inter-planar spacing at angle $\psi$

$\AA$

$d_{n} \quad \begin{aligned} & \text { Inter-planar spacing of normal } \\ & \text { surface }\end{aligned}$

$\AA$

This equation allows us to determine from two measurements made in the direction of the stress to be find and a plane normal to the surface. The best method to finding residual stress is the $\left(\sin ^{2} \psi\right)$ method. At different psi tilts, a number of XRD measurements are made [7]. The 2-theta peak position or inter-planar spacing is tested and plotted that illustrated in Figures (11\&12).

This equation allows us to determine from two measurements made in the direction of the stress to be find and a plane normal to the surface. The best method to finding residual stress is the $\left(\sin ^{2} \psi\right)$ method. At different psi tilts, a number of XRD measurements are made [7]. The 2-theta peak position or inter-planar spacing is tested and plotted that illustrated in Figures (11\&12).

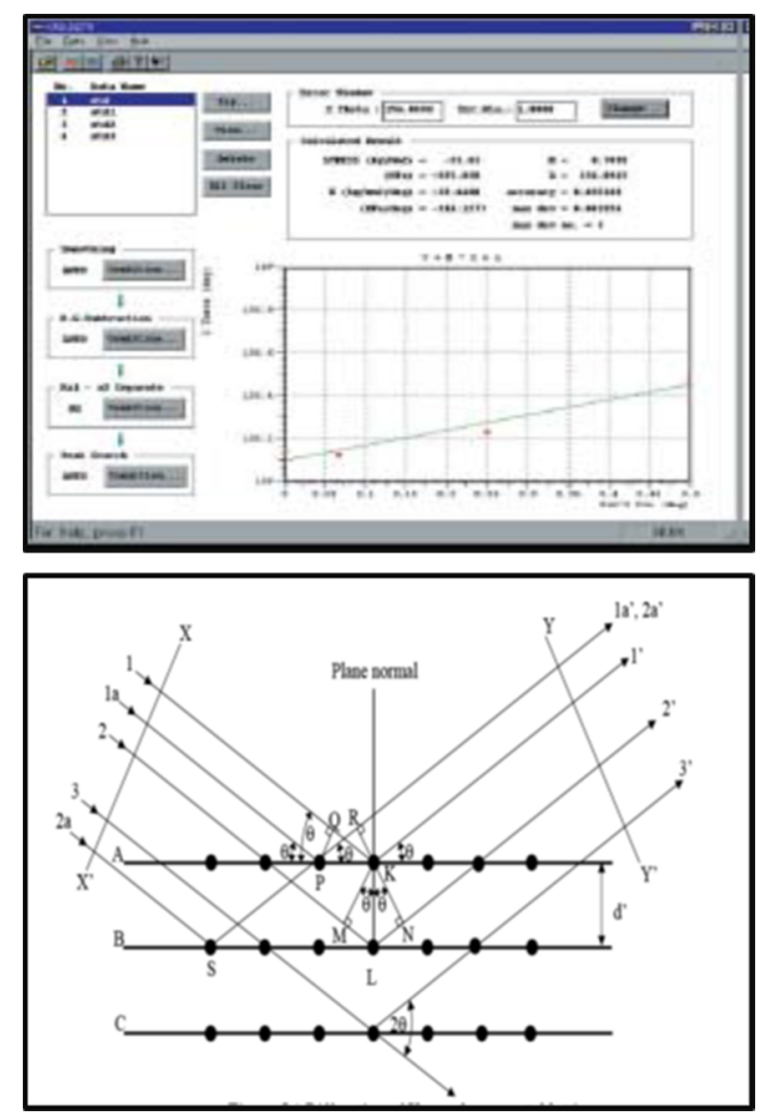

Fig. 11. Set up for residual stress measurement and residual Stress Analysis Result Screen [6].

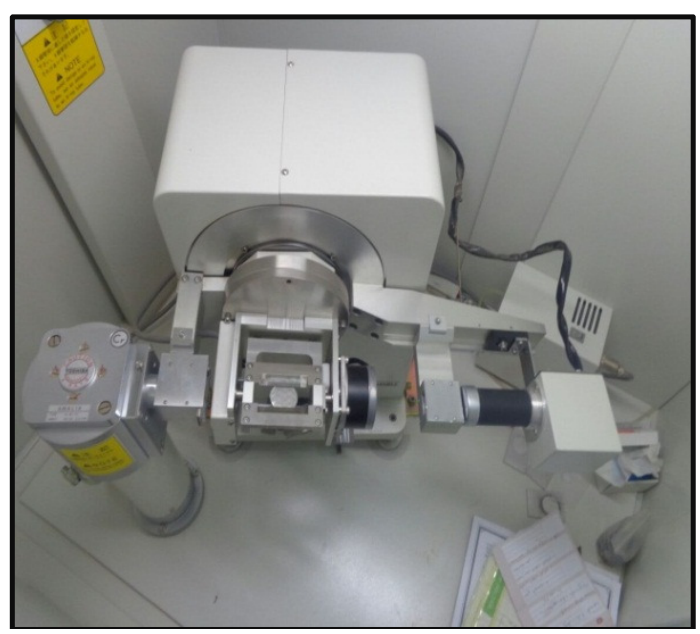

Fig. 12. Spectrometer and specimen holder in XRD6000. 


\section{Results and Discussion}

In order to compare the effect forming processes on residual stresses between single plate $(0.9) \mathrm{mm}$ and bottom plates $(0.9) \mathrm{mm}$ with change in thickness and insert material or lubrication between two plates, but thickness of bottom plates is constant for all experiments $(0.9) \mathrm{mm}$, the results have been divided into three groups and study effect changes in thickness of top plate and material or lubrication between two plates on residual stresses for bottom plates, these groups are as follows:

1. The first group includes the bottom plates for experiments $(4,7,10,13,16)$ in which different in material or lubrication were used Polymer, Grease, $\mathrm{Mos}_{2}$, Grease with Graphite and Without anything between two plates with same thickness of top plate (0.5) $\mathrm{mm}$ for all experiments in order to know its effect on residual stresses for bottom plates. Fig. (13) shows residual stresses for bottom plates are larger than those of a single plate and Graphite with Grease have less residual stresses and Mos2 has the largest residual stresses.

2. The second group involves the bottom plates for experiments $(5,8,11,14,17)$ which have the same parameters and levels of the first group, but they differ in thickness of top plate $(0.7) \mathrm{mm}$ for all experiment. Fig. (14) Shows that the residual stresses for bottom plates are larger than those for a single except when using graphite with grease which have less residual stresses than single plate and all other experiments while grease has the largest residual stresses.

3. The third group includes the bottom plates for experiments $(6,9,12,15,18)$ which have the same parameters and levels to the first group, but differ in thickness of top plate $(0.9) \mathrm{mm}$ for all experiments. Fig. (15) shows residual stresses for bottom plates are less than for single plate except when using Mos2 or grease which have larger residual stresses than single plate and all other experiments.

On applying the previous schemes to the influence change in material or lubrication between two plates, the thickness of top plate is constant for each diagram and thickness of bottom plates is $0.9 \mathrm{~mm}$ for all experiments. Figure (16) shows the effect of change in thickness of top plate on residual stresses for bottom plates and concludes that residual stresses decreased when thickness of top plate increased.

Table 3,

Results of Residual Stresses Measurements.

\begin{tabular}{|c|c|c|c|c|}
\hline $\begin{array}{l}\text { Exp. } \\
\text { No. }\end{array}$ & $\begin{array}{l}\text { Lub. or Material } \\
\text { between Plates }\end{array}$ & Position of Plate & Thickness of Plate & Residual Stresses measurement \\
\hline 1 & - & Single & 0.5 & 59.342 \\
\hline 2 & - & Single & 0.7 & 68.23 \\
\hline 3 & - & Single & 0.9 & 90.526 \\
\hline 4 & Without & Bottom & 0.9 & 117.754 \\
\hline 5 & Without & Bottom & 0.9 & 90.443 \\
\hline 6 & Without & Bottom & 0.9 & 70.769 \\
\hline 7 & Polymer & Bottom & 0.9 & 120.345 \\
\hline 8 & Polymer & Bottom & 0.9 & 93.435 \\
\hline 9 & Polymer & Bottom & 0.9 & 72.355 \\
\hline 10 & Grease & Bottom & 0.9 & 144.461 \\
\hline 11 & Grease & Bottom & 0.9 & 127.341 \\
\hline 12 & Grease & Bottom & 0.9 & 102.038 \\
\hline 13 & $\operatorname{Mos}_{2}$ & Bottom & 0.9 & 146.617 \\
\hline 14 & $\operatorname{Mos}_{2}$ & Bottom & 0.9 & 125.663 \\
\hline 15 & $\operatorname{Mos}_{2}$ & Bottom & 0.9 & 109.925 \\
\hline 16 & Graphite + Grease & Bottom & 0.9 & 111.811 \\
\hline 17 & Graphite + Grease & Bottom & 0.9 & 84.539 \\
\hline 18 & Graphite + Grease & Bottom & 0.9 & 60.173 \\
\hline
\end{tabular}




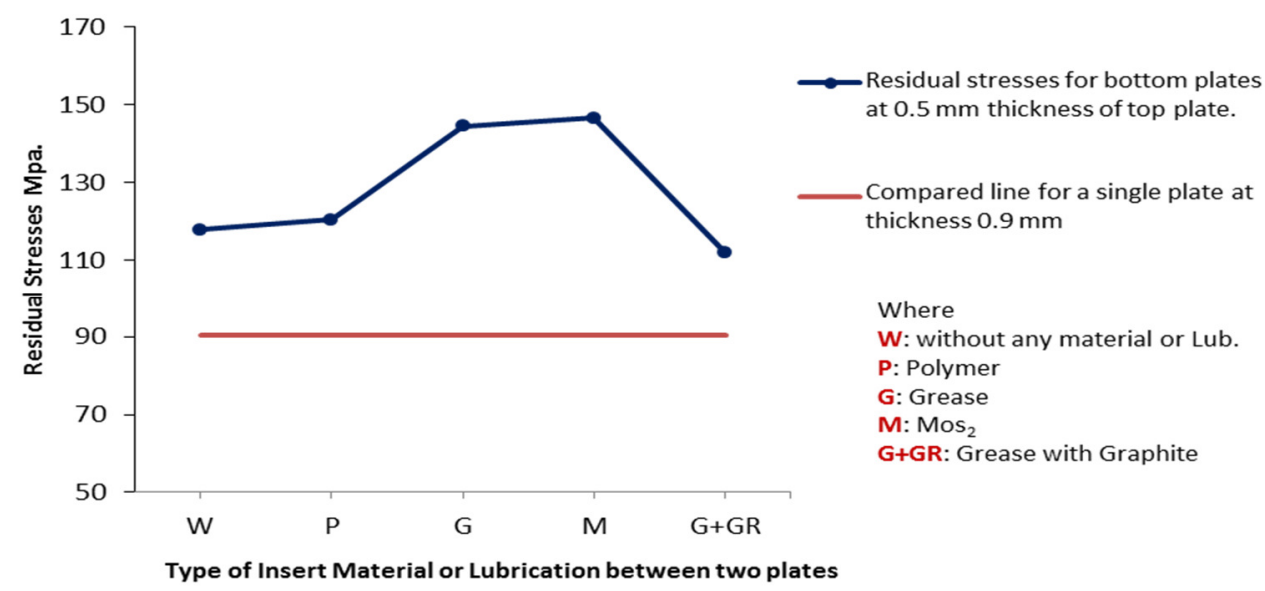

Fig. 13. Illustration the effect change in material or lubrication between two plates on residual stresses for bottom plates at $0.5 \mathrm{~mm}$ thickness of top plate and compared with a single plate.

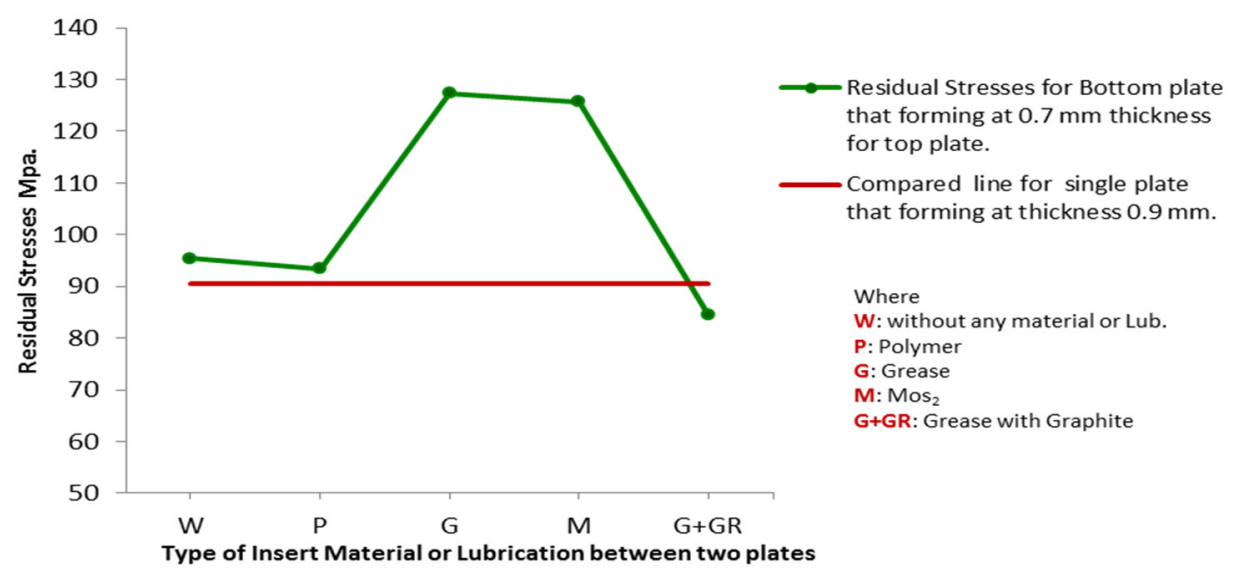

Fig. 14. Illustration the effect change in material or lubrication between two plates on residual stresses for bottom plates at $0.7 \mathrm{~mm}$ thickness of top plate and compared with a single plate.

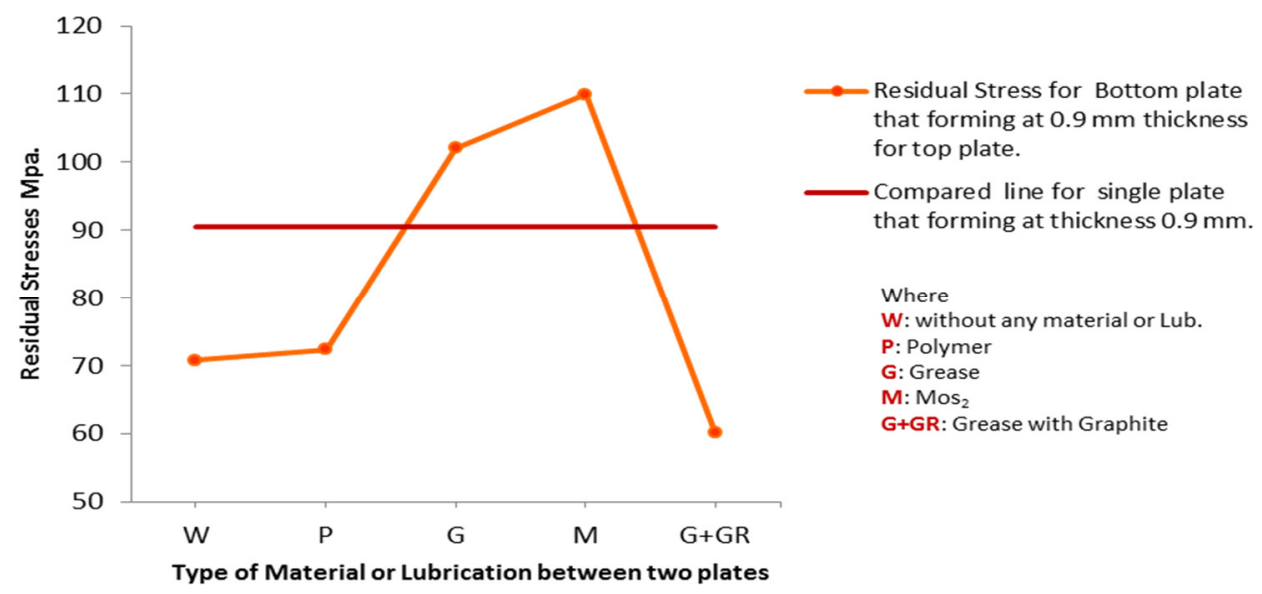

Fig. 15. Illustration the effect change in material or lubrication between two plates on residual stresses for bottom plates at $0.9 \mathrm{~mm}$ thickness of top plate and compared with a single plate. 


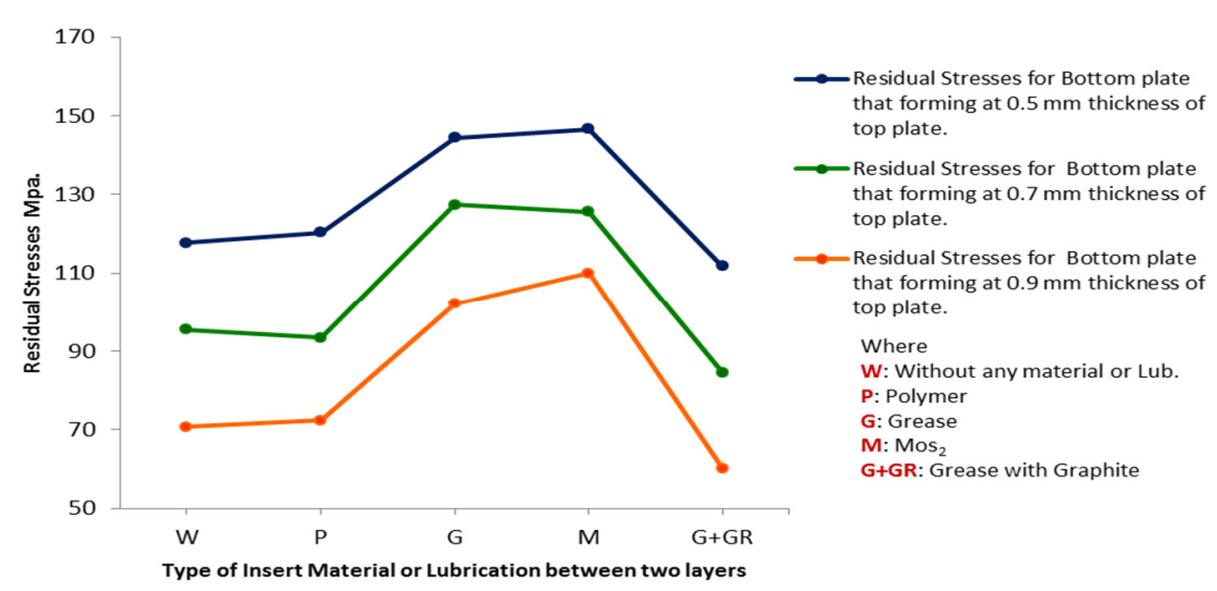

Fig. 16. Illustration the effects of change in thickness of top plates $(0.5,0.7,0.9)$ on residual stresses for bottom plates.

\section{Conclusions}

1. The maximum and minimum residual stresses, which is achieved from all experiments at bottom plate is (R.S = 146.617 \& R.S $=60.173 \mathrm{MPa}$.) respectively.

2. The change in thickness of top plate has a greatest effect on residual stresses for bottom plates than change in material or lubrication between two plates.

3. At increased thickness of top plate the residual stresses for bottom plate will be decrease.

4. Mos2 lubrication between two plates has greatest value of residual stresses on bottom plate.

5. Grease with Graphite lubrication between two plates has lowest value of residual stresses on bottom plate.

\section{References}

[1] Varithinr.r, Gandhinathan.r , Pandivelan.c, Jeevanavtham .k " Modling and Optimaization of process parameters of Single Point Incrmental Forming of Aluminum 5052 Alloy Sheet using Genetic Alogrithm-back Propagation Neural Network" International Journal of Mechanical and Production Engineering. Vol. 2, (2014).
[2] V. Naga chaitanya, Sunder singhsivam S.P, Dr. M. Gopal, Dr. G. Murali, "An Experimental Investigation on the Single Point Incremental Forming Of Aluminium Alloy" International Journal of Engineering Research. Vol. 3, pp. 155-159, (2014).

[3] M. Skjoedt, N. Bay, B. Endelt\& G. Ingarao " Single Point Incremental Forming using a Dummy Plate - MultiPlate Forming", 2nd International Conference on New Forming Technology, Bremen, (2007).

[4] www.engineeringtoolbox.comCRINA

[5] X-ray Diffraction Residual Stress Measurement, Proto Manufacturing Ltd, (2011).

[6] M.E. Fitzpatrick, A.T. Fry, P. Holdway, F.A. Kandil, J. Shackleton and L. Suominen, "Determination of Residual Stresses by X-ray Diffraction - Issue 2", Manchester Materials Science Centre, (2005).

[7] A. Pyzalla ,"Methods and Feasibility of Residual Stress Analysis by High-Energy Synchrotron Radiation in TransmissionGeometry Using a White Beam", Journal of Nondestructive Evaluation, Vol. 19, No. 1, (2000). 


\title{
دراسة تأثير التشكيل التظي|التزايديللصفائح المتعددة على الاجهادات المتبقية في الطبقة السفلية
}

\author{
عقيل صبري بدن**** \\ (الجامعة التكنولوجية

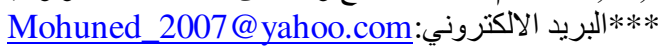

اسبل حمد عبد

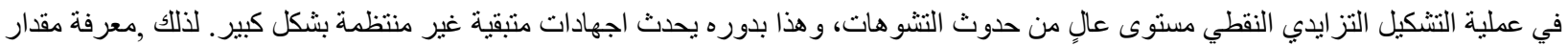

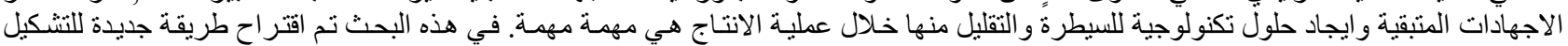

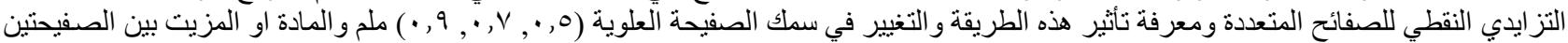
(polymer, grease, grease with graphite, mos 2 )

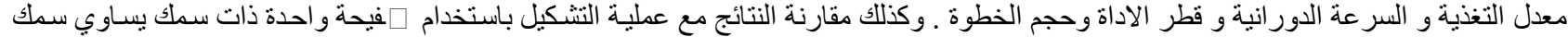

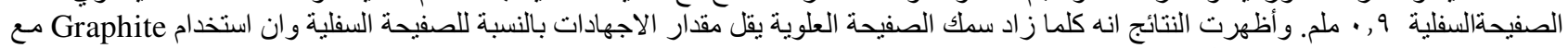

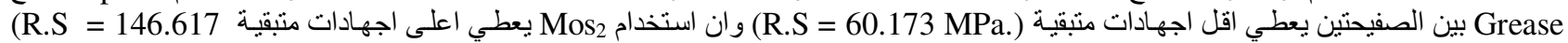

